\title{
EL PALUDISMO EN PALENCIA (1800-1804) A TRAVÉS DEL CANTO VOTIVO DEL JESUITA TOLRÁ
}

\author{
Antonio Astorgano Abajo \\ Real Academia de Extremadura \\ Email: astorgano1950@gmail.com \\ ORCID iD: http://orcid.org/0000-0001-5585-7499 \\ Fuensanta Garrido Domené \\ Universidad de Córdoba \\ Email: fuengarrido@gmail.com \\ ORCID iD: http://orcid.org/0000-0002-9895-2936 \\ Para Adriana y Mario Astorgano, \\ Vos nepotes carissimi.
}

Recibido: 7 junio 2016; Aceptado: 14 diciembre 2016

Cómo citar este artículo/Citation: Astorgano Abajo, Antonio y Garrido Domené, Fuensanta (2017), "El paludismo en Palencia (18001804) a través del Canto Votivo del jesuita Tolrá", Asclepio, 69 (1): p171. doi: http://dx.doi.org/10.3989/asclepio.2017.03

RESUMEN: El jesuita expulso Juan José Tolrá (Badajoz, 1739 - Madrid, 1830) fue un competente profesor de Humanidades y uno de los restauradores de la Compañía de Jesús (1812-1830) más influyentes. Retornado a España en 1798 y habiendo logrado eludir la segunda expulsión (1801), residió en Palencia en compañía de la familia de una hermana, donde contempló la hambruna y paludismo en el quinquenio 1800-1805. Ante este desastre humanitario compuso el Canto Votivo al Santísimo Cristo del Otero, que analizamos en el presente artículo. En bellas octavas reales narra el difícil contexto social, económico y sanitario palentino de la época. Al mismo tiempo aporta sinceras reflexiones morales, propias del ideario jesuítico y de su carácter personal, eminentemente reservado y conservador.

PALABRAS CLAVE: Tolrá; Paludismo; Palencia; Cristo del Otero.

\section{MALARIA IN PALENCIA (1800-1804) THROUGH THE VOTIVE CANTO OF JESUIT TOLRÁ}

ABSTRACT: The exiled Jesuit Juan José Tolrá (Badajoz, 1739-Madrid, 1830) was a competent teacher of Humanities and one of the restorers of the Society of Jesus (1812-1830) most influential. Returned to Spain in 1798 and having eluded the second expulsion (1801), in Palencia he lived in the company of the family of a sister, where he was witness to famine and malaria between 1800 and 1805. Considering this humanitarian disaster, he composed the Votive Canto to the Holy Christ of Otero, discussed in this article. In beautiful real octave, he narrated the hard social, economic and healthy context of the time. At the same time, he provides deep moral reflections, typical of Jesuit ideology and his personal nature, eminently reserved and traditionalist.

KEY WORDS: Tolrá; Malaria; Palencia; Christ of Otero.

Copyright: (C) 2017 CSIC. Este es un artículo de acceso abierto distribuido bajo los términos de la licencia Creative Commons Attribution (CC BY) España 3.0. 


\section{INTRODUCCIÓN}

Poco es lo que sabemos de la agitada vida del jesuita extremeño-palentino expulso Juan José Tolrá y Lafita (Badajoz 1739 - Madrid 1830). En su biografía podemos distinguir, al menos, las trece etapas vitales siguientes: 1a. Infancia y niñez (1739-1753) en diversas ciudades, siguiendo al regimiento de su padre. 2a. Noviciado en Villagarcía de Campos (1753-1755). 3a. Estudios eclesiásticos de filosofía y teología en Salamanca (1755-1763), donde se ordenó sacerdote en 1762. 4a. Operario y tercera probación en Valladolid (1763-1764). 5a . Profesor de Gramática en el colegio de Santiago de Compostela (1764-1765). 6a. Ministro en el colegio de La Coruña (1765-1767). 7ạ. Viaje y destierro en Calvi (Córcega, 1767-1768). 8a. Destierro en Bolonia antes de la extinción de la Compañía (1768-1773). 9a. Profesor de Humanidades en varias ciudades de Italia (1774-1798). 10a . Retorno a España (1798-1830). 11a . Escritor rentista en Palencia (17981808). 12a. Guerra de la Independencia (1808-1815) en Asturias y otros lugares, a la sombra del marqués de Santa Cruz de Marcenado. 13a. Jesuita restaurador en Madrid (1815-1830). Ahora solo podemos fijarnos en un aspecto de la etapa 11 a relacionado con la epidemia de paludismo en Palencia, sin duda la más grave que afectó a las Castillas desde el siglo XVI.

Como es sabido, en el Antiguo Régimen, a falta de medicamentos científicos eficaces para luchar contra la enfermedad, se acudía a remedios espirituales mediante frecuentes "rogativas". Pocas veces esas plegarias cristalizaban en bellos poemas que, además, describiesen con objetividad la triste situación ciudadana. Este es el caso del Canto Votivo, A la milagrosa ymagen del santíssimo Christo del Otero, que podemos fechar en el año agrícola de 1803-1804. ${ }^{1}$

\section{EL RETORNO DE TOLRÁ A PALENCIA EN 1798 Y SU PERMANENCIA VIGILADA ALLÍ DESDE 1801 HASTA 1808}

Las dramáticas circunstancias en que empezaron a volver los jesuitas desterrados en 1797 pueden verse en nuestro estudio sobre el P. Mariátegui (Astorgano, 2011). El provincial P. Morey narra el retorno de Tolrá a España con bastantes imprecisiones, pues Godoy permitió el regreso no para servirse de los ex jesuitas como enfermeros en las epidemias de 1800 , sino forzado por el maltrato que los revolucionarios franceses, que habían invadido Italia en 1796, estaban dando a los ignacianos españoles. ${ }^{2}$ Varios de los jesuitas retornados murieron afectados por la epidemia, como los americanos que estaban en Cádiz esperando embarque para sus países. Por su parte, Lorenzo Hervás y Panduro (1800), residente en Horcajo de Santiago (Cuenca), a lo largo de 1800 recibió insistentes invitaciones de sus amigos de la Real Sociedad Bascongada de Amigos del País para que se trasladase al País Vasco ante el peligro de contagio. ${ }^{3}$

Después de leer el Canto Votivo, cabe la duda de si Tolrá "asistió a los apestados", como dice Morey, en la Palencia de 1800-18054. De haber sido así, habría sido una manera de gratitud a las autoridades municipales, que tanto estaban haciendo por librarlo del segundo destierro.

\section{CONTEXTO SOCIOECONÓMICO Y SANITARIO DEL CANTO VOTIVO (1800-1805)}

Políticamente, el conde de Montarco, Juan Francisco de los Heros, presidente del Consejo de Castilla (1803-1805), tuvo que afrontar los momentos más difíciles, siendo el único que tomó medidas efectivas contra la hambruna con la importación masiva y planificada de trigo extranjero. Al respecto, son varias las circulares del conde a lo largo de 1804 (Sánchez, 1805, pp. 415-418).

Para conocer el contexto socioeconómico y sanitario de estos años contamos con los estudios específicos de Marcos Martín (1984 y 1985) y García Colmenares (1987 y 1998), que resume al primero, complementados con los de Reguera Useros (1985), Herrero Puyuelo (1987), Díaz Palenzuela (2002) y Parcero Torre (2003). Para el médico sanitario, es importante el análisis de Riera Palmero (1987), que se basa en el insustituible opúsculo del cirujano Agustín Argüello y Castrillo, Dictamen físico-médico-político sobre las epidemia de tercianas que por cerca de tres años reina en el Pays de Campos, y particularmente en su capital la ciudad de Palencia, 1802, la descripción más específica del contagio epidémico de tercianas iniciado en $1800 .{ }^{5}$ Son complementarios el contemporáneo Villalba (1802-1803), Anes (1970), los hermanos Peset Reig (1972), Carvalho (1972), López Gómez (1994), Riera Palmero (1982) y Llopis Agelán y Sánchez Salazar (Llopis y Sánchez, 2014). Además, es imprescindible acudir a los distintos archivos de Palencia, bastante completos al respecto. ${ }^{6}$

Sabemos que desde la grave y generalizada epidemia de 1786, que afectó a todas las regiones españolas excepto la cornisa cantábrica, se venían reiterando brotes estacionales de paludismo en forma endémica, una de cuyas mayores incidencias se alcanzó en 18001805. Anticipemos que realmente fue una crisis demográfica muy grave, según confirman los más recien- 
tes estudios, que afectó a las dos Castillas, pero sobre todo a Palencia. Según Llopis y Sánchez, los años 1803 y, sobre todo, 1804 constituyeron el núcleo central de esta crisis, periodo en el que nosotros fechamos la composición del Canto votivo de Tolrá. Comparando su incidencia en siete provincias castellanas, concluyen que la intensidad de la mortalidad fue netamente superior en Palencia, Guadalajara, Burgos y Zamora que en Albacete, Ávila y Ciudad Real. Refiriéndose a la Provincia de Palencia, Llopis y Salazar afirman que el destrozo ocasionado en la población palentina en 1802-1806 fue superior al resto de las provincias examinadas. La sobremortalidad de tal quinquenio habría eliminado el $12,6 \%$ de Palencia, si bien en su capital debió de ser mayor. En todo caso, parece exagerado el cálculo que había hecho Marcos Martín, que habla de que Palencia perdió durante ese periodo casi la mitad de su población, sin tener en cuenta que muchos de los muertos eran forasteros pobres venidos de los pueblos para intentar aliviar su situación (Llopis y Sánchez, 2014). Para Llopis y Sánchez, las pérdidas humanas se habrían elevado en ambas Castillas al 8,8\%.

Por otro lado, del examen de los libros de bautismos de diversas localidades resulta que la provincia de Palencia fue la que menos nacimientos tuvo, concluyendo que "Palencia aparece como el territorio más afectado por el revés demográfico de los primeros compases del siglo XIX" (Llopis y Sánchez, 2014, p. 17). Las noticias del Dictamen de Argüello sobre el brote de fiebres tercianas en Palencia coinciden con los datos de los libros de acuerdos de este Ayuntamiento, cuyas referencias evidencian la inquietud ciudadana y las medidas adoptadas frente al contagio. Argüello, además de relatar el proceso de las tercianas acaecido en Tierra de Campos de 1800 a 1802, describe la topografía y el estado sanitario de la capital palentina.

En las actas municipales, además, se hace presente la gran multitud de enfermos que, por no tener médico, no pueden medicarse ni curarse y tampoco pueden ser recogidos en el hospital General de San Antolín por no haber camas suficientes. Como la epidemia se extendía cada día más, el Ayuntamiento designó a dos síndicos, Felipe de Bedoya y Lorenzo Sanz Sedano, quienes, ante el elevado número de enfermos, dispusieron que se nombrasen dos personas de cada parroquia, con "sentimientos de humanidad", para que visitaran a los enfermos. Que todas estas medidas eran insuficientes, ante el volumen y la gravedad de la epidemia, lo atestiguan las reiteradas peticiones de ayuda y las continuas referencias a la deficiencia y falta de medios materiales. Las demandas se dirigen, en líneas generales, sobre la necesidad de nuevos fondos para dotar nuevas camas y a los necesarios medios materiales y alimentos para los enfermos. Por lo tanto, en dos direcciones principales se orientó la lucha sanitaria contra la epidemia: incrementando la infraestructura sanitaria con medidas de carácter económico y solicitando la colaboración entre los facultativos médicos y quirúrgicos (Riera Palmero, 1987, pp. 672-675). De hecho, Argüello encabeza su Dictamen con la siguiente cita: "A los magistrados corresponde vigilar sobre la salud de los pueblos; y a los físicos ayudarlos con sus luces para el acierto de sus providencias" (Argüello, 1802, p. 1), es decir, los aspectos socioeconómicos y los sanitarios están íntimamente relacionados. Al clero, entre el que se encuentra Tolrá, le corresponde, a su vez, ayudar con rogativas privadas y públicas, reseñadas en las actas del cabildo catedralicio y del Ayuntamiento palentinos, y cuya muestra literaria más notable es el Canto votivo que comentamos.

Por otra parte, Pérez Moreda demostró la estrecha interdependencia de hambre y enfermedad, entendiendo ambos términos en sentido lato, de manera que no se puede hablar de una crisis de mortalidad puramente epidémica o de subsistencias, sino de una crisis mixta (Pérez Moreda, 1980 y 1984). Por lo tanto, es difícil generalizar sobre las causas de la crisis demográfica de 1800-1805. Si en algunas regiones pudo haber escasez de alimentos, en otras fue más un fenómeno de pánico, de temor al desabastecimiento, lo que estimuló las prácticas de acaparación, ya de por sí bien desarrolladas entre los estamentos privilegiados y rentistas. ${ }^{7}$ Todo ello, sin perder de vista la realidad de las escasas cosechas de fines del siglo XVIII y primeros años del XIX ni las malas perspectivas para la cosecha de 1804. A ello habría que añadir la parca estructuración o inexistencia del mercado nacional, que no podía solucionar o compensar las desigualdades productivas regionales. Todo repercutía, al final, en la fuerte oscilación de los precios. De ahí, que esta crisis deba interpretarse como "mixta", por la estrecha relación existente entre la crisis de subsistencias del Antiguo Régimen, como punto culminante de más de 15 años de inflación de los productos alimentarios básicos, y el desarrollo de una nueva epidemia de fiebres palúdicas (tercianas y cuartanas), fiebre amarilla y, probablemente, tifus exantemático; fiebres reiteradamente aludidas por Tolrá ${ }^{8}$ que fueron más graves y persistentes para los adultos que para la población infantil, menos afectada (García Colmenares, 1998, pp. 128-129). 
Aparecida la epidemia, las instituciones pusieron en movimiento el lento aparato administrativo, medidas preventivas que fiaban todas sus posibilidades al aislamiento mediante "cordones sanitarios o militares" a la epidemia o a los lugares epidemiados. Y en estos, las medidas no van más allá, dado el escaso nivel de conocimientos médicos, de algunas normas de higiene y sanidad pública, como la desinfección o fumigación con productos químicos o plantas aromáticas (Baena, 1988, pp. 4-10). Esto queda reflejado en el Canto votivo de Tolrá, donde se plasman las crisis de subsistencia y mortalidad entre 1800 y 1805 y donde es evidente la concatenación "mala climatología" ("sequedad funesta"). ${ }^{9}$ Arruinado el campesinado, se traslada a la ciudad ${ }^{10}$, pero, no pudiendo socorrer al "famélico e indigente", nuestro jesuita solo puede rezar para que se levante el "azote" de la epidemia. ${ }^{11}$

\subsection{Año agrícola 1803-1804, el más probable de la composición del Canto votivo}

En el verso 25 Tolrá habla de que ya habían pasado tres años ("tres veces del Zodíaco los signos") sufriendo la crisis económico sanitaria; en el 47 dice que "si se cumple un lustro infausto..."; luego el Canto votivo fue compuesto a lo largo del cuarto año, es decir, en 1803-1804, teniendo en cuenta que los primeros casos del nuevo rebrote de paludismo o fiebres tercianas fueron en la primavera-verano de 1800. En los versos 83-84, Tolrá comenta que “asaltando prosigue más terrible / por medio lustro a la vacea gente", lo que podría adelantar la fecha a 1803, en función de cuándo considerase el jesuita que empezó la epidemia.

El invierno de 1802 fue muy riguroso y en la primavera siguiente faltaron las aguas necesarias. La sequía se enseñoreó otra vez de los campos y, como consecuencia, la cosecha de 1803 fue pésima. Se abre, a partir de entonces, un periodo de más de dos años durante el cual la crisis de subsistencias y la oleada epidémica alcanzan su mayor intensidad, sin que se produzcan, como en años anteriores, breves pausas de relativa bonanza. Ya antes de la recogida de la cosecha de 1803 se habían tomado las primeras medidas para atajar la carestía que se avecinaba. En el ayuntamiento del 1 de julio de 1803 se dio parte de que, por la gran sequía, se habían alterado extraordinariamente los precios del pan y que, para contenerlos, la Junta del pósito había resuelto panadear sus existencias concertándose con los panaderos, quienes pagarían la carga de trigo a 290 reales, a cambio de vender el pan a 20 cuartos. $^{12}$
Mientras las autoridades locales procuraban aliviar la hambruna, se padecían los embates de la epidemia de tercianas, que había reaparecido de nuevo a finales de la primavera de 1803 , confundiéndose durante el invierno de ese año con otras enfermedades y prolongándose en 1804 con una violencia hasta entonces desconocida, como denuncian las cifras de defunciones de que disponemos. En este momento debió haber sido compuesto el Canto votivo al santísimo Cristo del Otero de Juan José Tolrá. Una vez más, sin embargo, se puso de manifiesto la incapacidad de los establecimientos benéficos, aquejados por problemas financieros, para atender a las necesidades que la crisis originaba, lo que contribuyó, seguramente, a acentuar sus consecuencias. Pero, quizá, el hecho que mejor da cuenta de la incapacidad del viejo sistema asistencial para afrontar con éxito la crisis sea la constitución de una Junta de policía y sanidad, según la Real Orden de 26 de diciembre de $1803 .{ }^{13}$ La creación de dicha Junta supone un primer paso en el proceso de secularización de la asistencia y de incorporación de este cometido a las esferas de atención de los poderes laicos (Marcos Martín, 1985, II, pp. 416).

Como ya hemos dicho, en 1804 son diversas las circulares oficiales remitidas por el Consejo de Castilla y su gobernador, el conde de Montarco, a los corregidores para prever el abasto de productos de primera necesidad de las principales ciudades, evitando así el hambre y sus secuelas. La crisis se superará muy lentamente. En 1804, la curva de defunciones se mantuvo sin interrupción por encima de la de las concepciones, registrándose, también, las cifras de desnatalidad más bajas. Este saldo negativo del movimiento de la población se prolongó durante la mayor parte del año siguiente, en que se manifestaron los brotes epigonales de la epidemia. La cosecha de 1805 no obligó a la toma de medidas de excepción, pero, pese a la menor incidencia de la crisis de subsistencias, la epidemia sí tuvo virulento desarrollo (García Colmenares, 1998, p. 135). No obstante, una cosa sí que es evidente: a medida que transcurrían los meses de 1805 , las referencias a la crisis en las actas capitulares o en los libros de acuerdo del Ayuntamiento son cada vez menores. Por otro lado, 1804 rompió con la tendencia decreciente de la producción agraria de los últimos años y, aunque la cosecha no fue abundante, se pudo encarar el futuro con más optimismo. Además, temerosas las autoridades de que se reprodujeran las necesidades de los años anteriores, habían seguido importando granos extranjeros (García Colmenares, 1998, p. 136). ${ }^{14}$ 


\subsection{Aspectos médico-sanitarios de la epidemia. Crisis demográfica}

La escasa integración del mercado nacional y su lento proceso en el siglo XIX posibilitó fuertes $\mathrm{Y}$ trágicas oscilaciones de precios para los jornaleros y las clases populares urbanas, palpable en la fase depresiva en las producciones agrícolas desde 1800 a 1815 (Kondo, 1990, p. 25). El rebrote de paludismo iniciado en 1800 fue grave en el otoño de 1802, desapareció en invierno y retornó en verano. Aunque no provocó una catástrofe demográfica, sí pudo acelerar el empobrecimiento y encarecimiento de la mano de obra por las elevadas hospitalizaciones. En los meses sucesivos se agravaron las consecuencias de la epidemia. En Palencia, normalmente con una media de 500 muertos al año, se pasó a 1000 o 1100 en 1803 y 1804. En esta ocasión concurrieron otras enfermedades, como la fiebre amarilla y el tifus, además de las malignas "fiebres tercianas o cuartanas" del paludismo.

El Dictamen físico-médico-político de Argüello obedece a una exigencia higiénico-sanitaria y es fruto de la tarea realizada durante el contagio. Su intención es higiénica y profiláctica, así como terapéutica, de la que se nos indican las pautas más importantes. El Dictamen se inserta en la corriente ilustrada de preocupación por los problemas sanitarios. Recoge la orientación y contenido de los escritos epidemiológicos de la España ilustrada, citando, entre otros, textos y autores de la segunda mitad del siglo XVIII, como José Masdevall. Es patente el influjo de la orientación hipocrática, sydenhamiana y antisistemática presente en la medicina española del siglo XVIII (Riera Palmero, 1987, p. 674). En su relato no solo se ocupa de la etiología y factores predisponentes, sino que aborda las áreas afectadas, su incidencia entre la población laboral y las condiciones desfavorables de los cementerios palentinos, posibles vectores de contagio. El estudio de las tercianas, sus formas cíclicas, los recursos terapéuticos y su prevención son temas destacados en Argüello. Además de las condiciones meteorológicas, las higiénicosanitarias de la ciudad de Palencia son consideradas como posibles causas de las epidemias, proponiendo algunos remedios: terraplenar las fosas más recientes, sacar extramuros el cementerio, desecar e higinienizar las balsas y aguas "paludosas" cercanas a la ciudad. Argüello atribuye, por tanto, las causas de las enfermedades a las emanaciones y miasmas pútridos, así como a los "efluvios invisibles"; en otras ocasiones atribuye la epidemia a las "sustancias vi- rulentas", a las "emanaciones pútridas de los cadáveres", al aire, al calor y a los corpúsculos, vapores y exhalaciones de la tierra. La población más afectada correspondió a la parroquia palentina de San Lázaro, que se componía de obreros y trabajadores de las fábricas de lana. Su gran número (más de 2000 operarios) motivaba condiciones insalubres, debido a su permanencia constante en los obradores con ventilación escasa. La parroquia de Santa Marina, una de las más afectadas, se componía principalmente de pobres jornaleros del campo "que por carecer de los medios necesarios para su conservación, se ha ensañado en ellos con más furor la epidemia" (Argüello, 1802, pp. 25-32).

Las referencias señaladas evidencian una constelación epidémica en la que se vieron involucrados otros procesos morbosos cuya naturaleza es de difícil precisión, presentándose procesos que asemejan encefalitis o cuadros meníngeos (soporosos, letárgicos, etcétera); en otras, se trata de cuadros respiratorios, gastrointestinales y cuyo polimorfismo recuerda virasis intercurrentes que muy bien pudieron afectar a la población. Se describen procesos pleuríticos, síndromes que se asemejan a nefritis, cuadros con disuria, retenciones de orina, erisipela, que Argüello las califica de "erupciones semejantes al sarampión". En suma, y según Riera Palmero, pudo muy bien haber una irasis, acompañada o no de exantemas, y ser la causa etiológica de buen número de cuadros morbosos que se engloban en el capítulo de epidemias de tercianas. Más demostrativos son los casos de parotiditis, de etiología inequívocamente viral y de los que Argüello da concretas noticias (Riera Palmero, 1987, pp. 677-678).

La epidemia palúdica acometió a toda clase de personas. En sus comienzos aparecieron tercianas y "algunos hemitriteos". Argüello las califica en soporosas, letárgicas, apopléticas y hemipléjicas. Algunas las describe como casos de tercianas, al no coincidir con el cuadro habitual de las fiebres intermitentes: "esto es, con parálisis de la mitad del cuerpo según la línea vertical, y pérdida de la voz, por lo que fue preciso recurrir a la quina" (Argüello, 1802, pp. 37). No parece inverosímil que junto a las tercianas coincidiesen otros cuadros febriles y morbosos falsamente confundidos. La referencia anterior y otras que aporta Argüello son bastante indicativas al respecto. La patología parece haber incluido casos de "cefaleas y hemicrania", afectación del oído, anginas, perineumonías, pleuritis y diversos procesos, como dolores de costado (Riera Palmero, 1987, p. 675). Esta 
complicada patología y multiforme sintomatología desconcertaba a los médicos y al jesuita Tolrá. ${ }^{15}$ Ante este panorama, el impacto social con bajo índice de población debió ser brutal. No solo fueron catastróficos los efectos demográficos, sino que toda la estructura productiva y comercial se desbarató, agudizando la crisis de subsistencias. Sirva de ejemplo el potente gremio textil del barrio de la Puebla de la ciudad, que se vio obligado a solicitar ayudas y rebajas en sus cargas impositivas para no cerrar sus talleres (García Colmenares, 1998, pp. 130-131). A la vista de esta situación, es comprensible que surgiese en el espíritu de Tolrá su emocionado Canto votivo.

\section{EL CANTO VOTIVO A LA MILAGROSA YMAGEN DEL SANTISÍSIMO CHRISTO DEL OTERO (CA. 1804)}

Como hemos dicho, en 1803-1804 Tolrá escribió un "canto votivo" A la milagrosa imagen del Stmo. Christo del Otero, que se venera extra-muros de la Ciudad de Palencia, sobre las presentes calamidades. Queremos Ilamar la atención brevemente sobre este poema, el único completo y manuscrito del propio Tolrá en 264 endecasílabos estructurados en 33 octavas reales.

La política económica ilustrada, con magníficos resultados económicos en el reinado de Carlos III, no permitió un aumento de la producción equiparable al de la población, y las crisis agrarias se sucedieron a finales del siglo XVIII, alcanzando su punto culminante en 1802-1805. Todo ello coincidió con la crisis demográfica española más grave después de las pestes del siglo XVI (García Ruipérez, 1999, p. 15).

El poema de Juan José Tolrá es una invocación a la milagrosa imagen del santísimo Cristo del Otero que se venera extramuros de la ciudad de Palencia, una de las devociones populares más arraigadas de Palencia con raíces míticas visigodas (Fernández Conde, 2007), mezclada con el culto a un Santo Toribio y a otra imagen de la Virgen María, las tres advocaciones religiosas situadas en un cerro (otero), que debió infundir respeto mágico desde la prehistoria (San Martín Payo, 1985; Fernández Morate, 2009). Como jesuita y palentino, Tolrá compuso este poema sobre "las presentes calamidades" presumiblemente hacia 1804 , pues alude a la hambruna-epidemia iniciada en 1800 .

Las imágenes milagrosas de Cristo Crucificado eran objeto de mucha devoción en Palencia, ámbito esencialmente rural a principios del siglo XIX, según los datos remitidos a Tomás López por los respectivos párrocos (Egido, 1995, pp. 11-29). En la ermita de Nuestra Señora, en la cima del Otero, también se venera al Santo Cristo; dos advocaciones principales que durante siglos han compartido la titularidad. El altar mayor lo ocupa el Cristo Crucificado y uno lateral, la Virgen con el Niño. Conocida la situación topográfica de la ermita, ambas imágenes han sido testigos de las tempestades y calamidades de la climatología palentina. La imagen del Santo Cristo del Otero, enmarcada en un sencillo retablo neoclásico, es una emotiva talla del siglo XVI descrita al detaIle por Fernández Morate (2009, p. 28). La devoción popular a este Cristo, "que se Ilama vulgarmente Cristo del Otero" (Becerro de Bengoa, 1874, p. 172), remonta al siglo XV. El fervor a este Cristo está unido, por lo general, a días de necesidad para la gente palentina ocasionados por grandes sequías (Fernández Morate, 2009, pp. 28-29). Así, cuando Tolrá retornó a Palencia (1798), el culto al Cristo del Otero estaba bastante reavivado conforme se agrandaba la catástrofe ocasionada por la hambruna y las epidemias palúdicas desde 1786. Si los acuerdos municipales reflejan los gastos de las rogativas, de las propinas y del mantenimiento de la ermita, los acuerdos del cabildo catedralicio destacan las dificultades climatológicas y las malas condiciones del camino que llevaba al Otero. El Cabildo, en 1792, arregla el camino y ensancha la plazuela de la ermita (Fernández Morate, 2009, pp. 80-81).

Por otro lado, calificar el poema de Tolrá como "Canto votivo", es decir, dirigido a una divinidad para implorar un favor, tiene más aplicación en la literatura de Italia, donde había residido Tolrá desde 1767 a 1798, que en la española. Es un subgénero poético empleado tradicionalmente como canto de altar, para ofrecerlo a alguna divinidad, y relacionado con temática triste y cruel o jubilosa y de acción de gracias (Reder Gadow, 2013, pp. 147-158). Diríamos que el poema tolriano es una de las muchas ofrendas votivas, íntimas en este caso, dejadas ritualmente en uno de los lugares más sagrados de Palencia para ganar el favor divino. Tolrá fue un profundo conocedor de la literatura grecolatina y de la Sagrada Escritura, como humanista y como culto jesuita. En este contexto intentaremos enmarcar el Canto votivo.

Parece claro y lógico, en este sentido y en este contexto, el influjo de ciertos libros bíblicos en un ex jesuita, como Tolrá, que se dirige a la imagen más venerada de su ciudad. Así, toma del Evangelio de San Mateo el lema de todo el poema ("Señor, salvadnos, porque perecemos"). Hay, asimismo, dos referencias a San Lu- 
cas. La primera, cuando alude al episodio del rescate, por parte de Cristo, de los apóstoles cuando pescaban. ${ }^{16}$ Es una bella alegoría con la que Tolrá comienza la narración de la trágica situación de Palencia:

"Así un día clamaban fluctuantes / vuestros mismos Apóstoles queridos, / cuando en fiera borrasca naufragantes, / ya se veían casi sumergidos. / Vuestro amor en tan críticos instantes / no fue sordo a sus llantos y gemidos, / y aunque antes [Jesús] parecía somnoliento, / despertó y aquietó la mar y el viento" (versos 9-16).

La otra cita a San Lucas es a través de un comentario de San Jerónimo:

"Es nuestra fiebre la avaricia ciega. / Es nuestra fiebre la ambición profana; / fiebre sensualidad que al alma niega / estar sujeta, como a soberana; / fiebre es la ira, que a delirio llega; / fiebre es soberbia entumecida y vana. / Ningunas fueran nuestras aflicciones, / si no hubiera contagio de pasiones" (versos 137-144).

Dos son las referencias del Evangelio de San Juan. En la primera se califica a Jesús como "Palabra de vida":

“¿A quién iremos cuando a Vos no vamos? / Pues palabras tenéis de eterna vida / Una decid, Señor, que deseamos, / de perdón, de piedad, si merecida / ésta no ha sido, ahora os recordamos / palabra por Vos mismo repetida, / palabra en que mostró vuestra dulzura / cumplir lo que antes fue de Vos figura" (versos 193-200).

La segunda, cuando Cristo elevó la cruz a símbolo de salvación:

"Así, Salvador nuestro, Vos dijisteis / que debíais en cruz ser exaltado / para que los que en ella redimisteis / de la primera muerte del pecado, / creamos la palabra que nos disteis, / de que todos, si a Vos crucificado / ojos y alma contrita levantamos, / por herida mortal no perezcamos" (versos 233-240).

Es parecida la postura de Jeremías y Tolrá como interlocutores con la divinidad a favor de sus pueblos, que, sintetizada en las súplicas de Tolrá y de Jeremías ${ }^{17}$, relatan el drama de su existencia personal y la de sus pueblos. Asimismo, aunque las circunstancias de hambre y muerte descritas por Tolrá en la primera parte del Canto votivo hacen pensar en los sufrimientos de Job, sin embargo, en la segunda parte, el pueblo palentino aparece como pecador y culpable, por lo que nos vienen a la mente algunos salmos que no aparecen explícitamente aludidos.

Las súplicas dirigidas a Dios implorando perdón por los pecados personales, o de todo el Pueblo, o pidiendo amparo en situaciones de peligro que se abaten sobre la nación, están bien documentadas en el antiguo Israel, a través de las oraciones llamadas "de súplica" y de algunas celebraciones particulares. ${ }^{18}$ En ese contexto es donde se sitúan los salmos de súplica, proferidos por orantes individuales en nombre propio o recitados en la asamblea litúrgica. De hecho, por sus características conviene distinguir estas dos categorías de salmos: de súplica individual y de súplica colectiva o pública, que tienen relación con otros libro bíblicos de temática similar, como Isaías, aludido por Tolrá al relatar el episodio de Senaquerib (versos 173-174), o el Libro de las Lamentaciones atribuido a Jeremías. ${ }^{19}$ Durante toda su vida, Tolrá se mostró apasionado de la poética de los salmos. Otras congregaciones religiosas, como los agustinos, preferían, para consolarse en los tiempos difíciles, el Canto de Job, como se evidencia en Fray Luis de León. Ambos libros son de lo mejor de la poesía religiosa hebrea, incluidos entre los llamados Libros sapienciales, aunque no siempre se considera que todos los salmos corresponden a la tradición sapiencial (Franquesa, 1966; Keller, 1985, pp. 211-220; Ravasi, 1985; Morla 1994).

En cuanto a la estructura del poema, esta sigue, en líneas generales, las cuatro partes de la Retórica clásica (exordio, narración, argumentación y peroración), si bien la argumentación y la peroración se funden a partir de la estrofa 18 (versos 137-255). Está encabezado, como se ha indicado, por el significativo emblema "Domine, salva nos, perimus", que resume el tema. Este lema se reitera varias veces a lo largo de las 33 estrofas a manera de estribillo, principalmente en las estrofas primera ${ }^{20}$ y en la $33^{21}$. El resto presenta una estructura típica de salmo. La introducción consta de una invocación del nombre de Dios, mediante una llamada confiada donde se recuerdan algunos atributos divinos que dan apoyo a la esperanza (poder, misericordia, fidelidad) y donde se pide ser librados de los males que afligen. Es la primera estrofa del Canto votivo:

"Cristo Jesús, salud de los mortales, / que sobre ese alto Otero venerado / remedio siempre fuiste a los males / del palentino pueblo atribulado; / éste entre las angustias más fatales / a Vos clama..." (versos 1-6).

En ella, además, se define el subgénero poético donde se puede enmarcar el "canto votivo": es una presentación de la invocación que el pueblo palentino hace al Cristo del Otero.

A continuación viene el cuerpo del poema, donde Tolrá expone los motivos de su súplica -la catástrofe 
humanitaria por la hambruna y las enfermedades y la presencia de los propios pecados- y lo que turba el alma: el miedo a la muerte, el abatimiento moral, los dolores físicos, etc. Las imágenes y figuras retóricas surgen espontáneamente en este Canto votivo, dando a la súplica un fuerte dramatismo y riqueza simbólica. Estas imágenes y figuras necesitan ser interpretadas mediante una adecuada decodificación. En el Canto votivo el cuerpo está perfectamente estructurado en dos partes, aflorando en la primera (versos 1-128) el Tolrá humanista al describir las circunstancias climáticas, sanitarias y socioeconómicas de Palencia, con referencias al mundo grecolatino (estrofas 1-16). En esta parte, al lector actual le es imprescindible conocer las circunstancias históricas de la Palencia del primer lustro del siglo XIX para comprender el poema tolriano. Sin embargo, el ciudadano palentino de la época no tenía ningún problema interpretativo al ser testigo directo de los hechos. Así, las calamidades empiezan por la sequía, descrita en las estrofas 4-6:

"Del clima inficionado los rigores / comunican su endémica influencia / al campo, la ciudad de habitadores / de la triste provincia de Palencia. / Campo, ciudad, provincia y moradores / ya temen su postrera decadencia; / del país, si se cumple un lustro infausto, / de hombres, reses y frutos queda exhausto" (versos 41-48).

Las estrofas siguientes describen las fatalidades que se enlazan y derivan de la sequía, afectando a todos los estamentos sociales, comenzando por el labrador ${ }^{22}$. Como consecuencia del hambre del campesinado se deriva la emigración a la ciudad, con cuyo hacinamiento se agravan las malas condiciones de la misma. ${ }^{23}$ Otros testimonios refieren esta corriente inmigratoria, por ejemplo en la sesión del 3 de enero de 1804 , donde los regidores palentinos tratan la frecuencia con que morían en Palencia los pobres forasteros ambulantes, "que emigrados de sus pueblos por la necesidad que padecen se recogen a las ciudades" ${ }^{24}$. Así pues, consecuencia de la emigración del campo ("colonos") a la ciudad es la extensión del hambre a las capas populares ("artistas y jornaleros") de la capital palentina, puesto que los habitantes de la ciudad ("el mediano cosechero"), antes generosos, ahora también sufren la escasez. ${ }^{25}$

Derivada de la sequía y del hambre es la peste, la otra calamidad de Palencia (estrofa 10) que llevaba soportando medio lustro. Tolrá narra la cronología de la crisis de 1800-1805, las malas cosechas por causas climatológicas que causan hambruna y epidemias:
"No se detiene aquí el desapiadado / tropel de nuestros males horroroso, / que la mies y alimento más menguado / sólo fueron anuncio pavoroso / del azote que estaba levantado, / sangriento, fulminante y ruinoso, / a cuya justa merecida saña / terror, fiebre, dolor, muerte acompaña" (versos 73-80).

Este mal es narrado en las estrofas 11-16, dedicando cada una a diversos aspectos del mismo. En la estrofa 12 describe cómo la peste es una fiebre voraz que se extiende por plazas, calles y casas. En la estrofa 13 se suceden los distintos y contradictorios cuadros clínicos de la epidemia: desde el sudor frío hasta las calenturas ardientes, pasando por la fiebre que aletarga a los pacientes. En la estrofa 14 vemos la imagen de la muerte que va dejando la peste (versos 109-112). A continuación, Tolrá presenta los segmentos de población afectados por la peste y la muerte en los lamentos de viudos y huérfanos (estrofa 15). En la estrofa 16 esboza la estampa de una madre que Ilora a su hijo tan deseado, con unos epítetos bastante prerrománticos:

"Prorrumpe en ayes y en amargo llanto / la tierna Madre, a quien la muerte impía / sin tener compasión de su quebranto, / le arrebata del seno, en que crecía, / el dulce hijuelo, deseado tanto. / Ayes... mas tantos son que un solo día / no se interrumpen, y aunque tan discorde, con nuestra mala suerte van acordes" (versos 121-128).

Después de la estrofa 17, de transición entre las calamidades físicas y las espirituales, surge el Tolrá sacerdote que ruega fervientemente al Cristo del Otero por su pueblo. En una segunda parte del cuerpo del salmo (canto votivo) se describen las calamidades morales de la sociedad (versos 137-264), pues Tolrá, como jesuita y con una visión providencialista y fatalista de la historia, cree que las desgracias (sequía, hambre, peste), en última instancia, no son una casualidad o mala suerte (versos 128-131), sino consecuencia de un castigo divino por las pasiones desenfrenadas del hombre contemporáneo. En esta parte, eminentemente moral y penitencial, se pueden distinguir dos subpartes: en la primera, se presenta a un Dios castigador y severo con el pecado y las pasiones (versos 137-184); en la segunda (versos 185-256), aparece el Dios generoso y dispuesto al perdón. En el Canto votivo hay claros ecos de los salmos penitenciales como plegaria (Bernini, 1953), en especial el Salmo 51 (Miserere) y el 130 (De profundis) (Owens, 1977; Ravasi, 2008).

Desde la estrofa 24 hasta la 32, la otra subparte del canto votivo-penitencial está dedicada a demostrar la generosidad del Creador (estrofa 25). Después de 
reconocer que el hombre contemporáneo está herido de pasiones ${ }^{26}$, Tolrá suplica al Cristo del Otero que lo socorra ${ }^{27}$. La última estrofa repite en gran parte, a manera de resumen, la invocación de la estrofa primera, pues presenta la apoteosis del pueblo de Palencia, postrado ante el Cristo del Otero, suplicando socorros, cerrando el poema con un verso que reitera el lema que introducía el poema:

"De esa colina [el otero], donde a cada hora / sois visto, y veis a nuestros ciudadanos, / donde la castellana feé os adora / constante desde siglos muy lejanos; / de Vos pendiente en esa Cruz implora / Palencia los socorros soberanos, / y con ella en clamar proseguiremos, / Señor, salvadnos, porque perecemos" (versos 257-264).

Esta segunda parte penitencial del poema presenta más dificultades de compresión, todas superables, por las constantes alusiones bíblicas. En algunos casos aparecen verdaderas imprecaciones (invectivas, protestas) que pueden desconcertar al lector si no tiene presente el género literario y que estas expresiones surgen de un deseo de justicia divina:

“¿Mala suerte? ¿Qué digo? ¡Ah! que mayores, / y voluntarios males no os oprimen, / en semblante de amigos, mas traidores. iCuán pocos son aquellos, que se eximen / de su halago y placer engañadores!" (versos $129-133)^{28}$.

Estas expresiones manifiestan, con simbolismos diferentes, la angustia y la espera en un inmediato cumplimiento de la petición:

"No necesita para castigarnos / abrir las cataratas de su cielo, / ni en un diluvio de aguas anegarnos, / como un tiempo anegó al mundano suelo; / y si quisiere vivos abrasarnos, / no le puede costar algún desvelo / hacer que de Pentápolis la historia / hoy renueve con fuego su memoria" (versos 161-168).

\section{A MODO DE CONCLUSIÓN SOBRE EL CANTO VOTIVO AL CRISTO DEL OTERO}

Para comprender el Canto votivo de Tolrá, apasionado humanista y convencido ignaciano, hay que contextualizarlo en el papel de la Iglesia española de finales del Antiguo Régimen, en general, y en las dramáticas circunstancias económico-sanitarias de Palencia en 1800-1805, en particular. A principios del siglo XIX la religión en España era una necesidad primordial para la mayoría del pueblo y un sacerdote culto, como Tolrá, se creía con suficiente autoridad moral como para encabezar una de las muchas rogativas que la sociedad demandaba (Revuelta, 2008, p. 165).
El poema está estructurado conforme a la mentalidad providencialista de la religiosidad popular de la época, es decir, en la primera parte se describen las adversidades climáticas y naturales, infundiendo el miedo y el remordimiento en los fieles al acusarlos de ser ellos los causantes de sus males por haber pecado. La catástrofe humanitaria era el correctivo, castigo divino y advertencia que Dios les mandaba por su mala conducta, todo exacerbado con un lenguaje apocalíptico. Después de presentar al Dios punitivo, la segunda parte del poema es la penitencial, pues se trata de reconducir la conducta de los fieles hacia el arrepentimiento con fervor religioso, como último asidero para sobrevivir. Esta interacción entre miedo, culpa y piedad con frecuencia terminaba en rogativas en forma de poemas, muchos de dudosa calidad. El Canto votivo se salva de esa mediocridad.

Literaria y formalmente es un poema notable, cuyas 33 octavas reales se leen con gusto, sin excesivos artilugios retóricos que dificulten su compresión. Por la necrológica tolriana que dejó Morey, sabemos que era aficionado a la poesía, aunque se haya perdido casi toda. Por el Canto votivo podemos intuir su gusto neoclásico, abiertamente contrario a las complicaciones formales del Barroco. Este poema tuvo las circunstancias de componerse en la peor epidemia que asoló Palencia desde el siglo XVI y de tener como autor a un jesuita expulso y riguroso humanista, curtido en mil peripecias vitales y todavía amenazado con una segunda expulsión (la de 1801, que logró esquivar). El resultado es una bella composición ajustada a las normas de las preceptivas poéticas clásicas sobre la octava real o heroica, donde es indudable el influjo de la Biblia, en especial de algunos salmos.

Aunque este jesuita siempre tuvo su vena patriótica de defensa de lo español, en el Canto votivo aparece más "lugareño", aportando detalles de las circunstancias de la catástrofe económico-sanitaria del primer lustro del siglo XIX en Palencia. Sintiéndose apreciado y respetado por el vecindario palentino, un agradecido Tolrá, de 65 años, ayudó a salir de la catástrofe sanitario-alimentaria con una plegaria dirigida al Santísimo Cristo. No es extraño, por tanto, que Tolrá se fijase en la milagrera imagen del diminuto y patético Cristo del Otero palentino, que solo descendía a la ciudad cuando era invocado en las rogativas. Todavía hoy suscita sentimientos de misterio, pero ahora a través de la estatua monumental de Victorio Macho, desde donde continúa protegiendo la ciudad (Lomba, 2002). 


\section{APÉNDICE \\ CANTO VOTIVO A LA MILAGROSA YMAGEN DEL SAN- TÍSIMO CHRISTO DEL OTERO}

[1] A la Milagrosa Ymagen del santísimo Christo del Otero, que se venera extramuros de la ciudad de Palencia. Sobre las presentes calamidades. Canto votivo. En Palencia, por don Juan Joséf Tolrrá, de la extinguida Compañía de Jesús.

\section{[Lema]}

$[2 \mathrm{a}]^{29}$ Domine, salva nos, perimus.

Mateo, 8 v. $24-25$

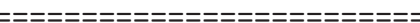

\section{[Exordio]}

\section{[Estrofa 1]}

[2b] Cristo Jesús, salud de los mortales, que sobre ese alto Otero venerado remedio siempre fuiste a los males del palentino pueblo atribulado (sic, atribuido);

5.-- éste entre las angustias más fatales

a Vos clama, cual nunca, desolado, temiendo ya los últimos extremos, Señor, salvadnos, porque perecemos.

\section{[Narración. Hechos históricos]}

[2]

Así un día clamaban fluctuantes

10.-- vuestros mismos Apóstoles queridos, cuando en fiera borrasca naufragantes, ya se veían casi sumergidos.

Vuestro amor en tan críticos instantes no fue sordo a sus llantos y gemidos, 15.-- y aunque antes parecía somnoliento, despertó y aquietó la mar y el viento ${ }^{30}$.

[3]

[3a] También nosotros en un golfo estamos de aflicción y desdichas porfiadas, desde donde los ojos levantamos 20.-- hasta esas vuestras rocas elevadas ${ }^{31}$, que han sido a cuantos en su pie habitamos manantial de piedades reiteradas.

¡Ah!, Señor, despertad, oíd, miradnos; perecemos, Señor; Señor, salvadnos.

[4]

25.-- Tres veces del Zodíaco los signos, tres la eclíptica el Sol ha iluminado ${ }^{32}$ sin que tengamos parte en sus benignos influjos; antes bien, Sirio irritado ${ }^{33}$ vomita con furor fuegos malignos 30.-- sobre nuestro terreno dilatado, y antes que pueda repararse el daño, su atrocidad renueva de año en año ${ }^{34}$.

[5]

[3b] Turbado el atmosférico elemento, su elástica virtud ya descompuesta ${ }^{35}$, 35.-- no hallan entre sus átomos fomento los húmedos vapores que detesta.

$\mathrm{O}$ si algunos admite, en un momento los aniquila sequedad funesta.

¡Ay! que solos no son el aire y cielo 40.-- nuestro justo castigo y desconsuelo.

[6]

Del clima inficionado ${ }^{36}$ los rigores comunican su endémica influencia al campo, a la ciudad y habitadores de la triste Provincia de Palencia. 45.-- Campo, Ciudad, Provincia y moradores ya temen su postrera decadencia; el país, si se cumple un lustro infausto, de hombres, reses y frutos queda exhausto.

[7]

[3bv] Se ve el campo agostado antes que verde, 50.-- y el labrador que en él sembró sus granos, sus granos y fatiga infeliz pierde, sin que la tierra a sus cansadas manos, aún lo que de ellas recibió, le acuerde, volviendo siempre sus esfuerzos vanos; 55.-- su familia al trabajo antes atenta, labor no encuentra y va girando hambrienta. 
[8]

Las aldeas, las villas y lugares

de colonos se van disminuyendo,

que abandonan sus patrios llares,

60.-- y el pan a la ciudad vienen pidiendo;

mas la ciudad envuelta en sus pesares,

ni los ajenos remediar pudiendo,

de uno y otro dolor se compadece,

y uno con otro mutuamente crece.

[9]

65.-[4r] Aunque sudan artista y jornalero,

y suben de alto precio su salario,

no llega el arte, aplicación y esmero

a ganar el sustento necesario.

El que antes fue mediano cosechero,

70.-- no halla en sus trojes más que el pan diario;

y si antes las abría francamente,

hoy las cierra al famélico e indigente.

\section{[10]}

No se detiene aquí el desapiadado

tropel de nuestros males horroroso,

75.-- que la mies y alimento más menguado

sólo fueron anuncio pavoroso

del azote ${ }^{37}$ que estaba levantado,

sangriento, fulminante y ruinoso,

a cuya justa merecida saña

80.-- terror, fiebre, dolor, muerte acompaña.

[11]

[4v] Este armado escuadrón fuerte, invencible, vengador de su Dueño Omnipotente,

asaltando prosigue más terrible

por medio lustro a la Vacea gente ${ }^{38}$.

85.-- No hay defensa ni escudo inaccesible,

que pueda resistir o hacerlo $(\mathrm{sic})^{39}$ frente,

y quien evita el golpe decisivo,

de solo su terror queda cautivo ${ }^{40}$.

\section{[12]}

Fiebre voraz, de Averno furia insana ${ }^{41}$, 90.-- en figura espantosa espectro infando, siempre sedienta de la sangre humana, plazas, calles y casas va infestando; sorda a remedios la cruel tirana,

y a Esculapio y sus Artes insultando ${ }^{42}$

95.-- para engañar, de tantas formas muda ${ }^{43}$, que cual su engaño sea, hasta hoy se duda.

[13]

[5r] Ya se muestra, de agudo frío, yerta, trémula, palpitante y convulsiva;

ya de abrasarse da la señal cierta 100.-- su piel, de internas llamas, expresiva; ya también, ni dormida, ni despierta, aletargada yace, y semiviva, sus síntomas tal vez ceder parecen, mas vuelven de improviso y se enfurecen.

[14]

105.-- No es tanta de la muerte la licencia, como de esta su hermana la arrogancia, porque del Juez Supremo la clemencia pone al mayor castigo en más distancia. Brama en tanto la muerte con vehemencia 110.-- pidiendo su ejercicio con instancia y aunque absoluto hasta ahora se le niega, más vidas que antes su guadaña siega.

[15]

[5v] En repetidos ayes ${ }^{44}$ lamentables resuenan viudos tálamos llorosos, 115.-- que acaban de perder a sus amables esposas o a sus jóvenes esposos. Familias y pupilos miserables ayes también repiten dolorosos, llamando en vano a la que fue su madre 120.-- o suspirando por el muerto padre.

[16]

Prorrumpe en ayes y en amargo llanto la tierna Madre, a quien la muerte impía, sin tener compasión de su quebranto, le arrebata del seno, en que crecía, 125.-- el dulce hijuelo, deseado tanto. Ayes... mas tantos son que un solo día no se interrumpen, y aunque tan discordes, con nuestra mala suerte van acordes. 


\section{[Estrofa de transición de los males físicos a los morales]}

[17]

[6r] ¿Mala suerte? ¿Qué digo? ¡Ah, que mayores, 130.-- y voluntarios males nos oprimen, en semblante de amigos, mas traidores! ¡Cuán pocos son aquellos, que se eximen de su halago y placer engañadores! Muchos por el contagio penan, gimen; 135.-- pero más que la fiebre y mal que lloran, otras ardientes fiebres nos devoran ${ }^{45}$.

[Parte moral. Argumentación y Peroración. Dios castigador y misericordioso]

\section{[Cristo, castigador del pecado]}

\section{[18]}

Es nuestra fiebre la avaricia ciega ${ }^{46}$.

Es nuestra fiebre la ambición profana;

fiebre sensualidad que al alma niega

140.-- estar sujeta, como a soberana; fiebre es la ira, que a delirio llega; fiebre es soberbia entumecida y vana. Ningunas fueran nuestras afliciones, si no hubiera contagio de pasiones.

\section{[19]}

145.-[6v] ¿Éstas, acaso, son menos furiosas a vista del castigo que sufrimos?

Si osadas fueron siempre, hoy mentirosas son más que nunca, cuando las oímos decir tan necias, como irreligiosas, 150.-- que cuantos males vemos, cuantos vimos, efectos son, que casual produjo de las físicas causas el influjo.

\section{[20]}

Sí. De ellas ${ }^{47}$ el azote se compone que la divina mano empuñar suele, 155.-- cuando sus golpes descargar dispone la ofendida justicia que le impele. No se trastorna, ni se descompone Naturaleza, aunque la herida duele, porque el Autor de la Naturaleza 160.-- en ella misma muestra su grandeza ${ }^{48}$.
[21]

[7r] No necesita para castigarnos abrir las cataratas de su cielo, ni en un diluvio de aguas anegarnos, como un tiempo anegó al mundano suelo; 165.-- y si quisiere vivos abrasarnos, no le puede costar algún desvelo hacer que de Pentápolis ${ }^{49}$ la historia hoy renueve con fuego su memoria.

[22]

No necesita para la tremenda 170.-- ruina de los pueblos delincuentes que un Exterminador Ángel descienda, como al Egipto [o] a las Asirias gentes, cuando Sennacherib ${ }^{50}$ desde su tienda muertos vio innumerables combatientes. 175.-- Basta en su mano un débil instrumento, para ser nuestra pena y escarmiento.

[7v] Débil nos pareció cuando empezaba este febril insulto contagioso.

Hoy prosigue agravándose y no acaba 180.-- porque quien lo dirige, aunque piadoso cual solo aviso entonces nos le enviaba, frustrado ahora viéndolo y ocioso, sin retirarlo, justamente quiso que pasase a ser pena el que era aviso.

\section{[Cristo misericordioso]}

185.-- Aviso y pena, oh Salvador amable, haced que ya enmendados [os] veneremos, y que nuestra dureza detestable hasta aquel precipicio no llevemos, de que está cerca nuestra vida instable ${ }^{51}$. 190.-- Señor, salvadnos porque perecemos, aún más que por castigos tan propicios, por la infección mortal de nuestros vicios.

[25]

[8r] ¿A quién iremos cuando a Vos no vamos? Pues palabras tenéis de eterna vida ${ }^{52}$ 195.-- Una decid, Señor, que deseamos, 
de perdón, de piedad, si merecida ésta no ha sido, ahora os recordamos palabra por Vos mismo repetida, palabra en que mostró vuestra dulzura 200.-- cumplir lo que antes fue de Vos figura ${ }^{53}$.

[26]

Errante el pueblo hebreo caminaba de Edom por los confines solitarios ${ }^{54}$, y a Dios, que con prodigios los guiaba, llegó a insultar con gritos temerarios, 205.-- porque ya del maná se desdeñaba, aunque era de alimento y gustos varios; mas de estas y otras culpas Dios, cansado, en muy pocos momentos fue vengado.

\section{[27]}

[8v] Aparécense millares de serpientes, 210.-- que penetrando el aire con silbidos, asaltan, muerden con rabiosos dientes a los israelitas fementidos, a sus heridas, más que el fuego ardientes, suceden ayes, llantos y alaridos ${ }^{55}$; 215.-- huyen sin saber dónde, se horrorizan, ya mueren muchos, otros agonizan.

\section{[28]}

A una vista tan trágica el profeta Moisés se conmueve, a Dios suplica por aquella nación pérfida, inquieta, 220.-- que penitente al fin su culpa explica. Condesciende el Señor y le decreta en la figura, que formar le indica, la mayor misteriosa medicina, que dio a los hombres su piedad divina.

225.-[9r] Expón, le dice, en elevada altura una serpiente de metal, que vean cuantos de la ponzoña y mordedura acometidos y dañados sean. Esta será señal cierta y segura 230.-- de la salud y vida que desean. Ya colocada, corren y se afanan todos por verla, y vista, al punto sanan.
[Apoteosis del pueblo palentino postrado ante el Cristo del Otero]

[30]

Así, Salvador nuestro, Vos dijisteis que debíais en cruz ser exaltado ${ }^{56}$ 235.-- para que los que en ella redimisteis de la primera muerte del pecado, creamos la palabra que nos disteis, de que todos, si a Vos crucificado ojos y alma contrita levantamos, 240.-- por herida mortal no perezcamos.

[9v] Heridos ya nos veis por cielo y tierra, que parecen cansados de sufrirnos, haciéndonos cada año cruda guerra sin querer acabarla hasta oprimirnos; 245.-- heridos de pasiones que en sí encierra nuestro infiel pecho, y para consumirnos son serpientes ocultas, que abrigamos; mas de ellas solas nunca nos quejamos.

Si fue símbolo vuestro la serpiente 250.-- para salud de todos erigida, también figura hasta hoy presente fue la hebrea nación, cuando escogida: si la hemos imitado delincuente, la imitamos ahora arrepentida; 255.-- y pues entonces una imagen vuestra fue su salud, sed Vos también la nuestra.

\section{[Conclusión]}

[10r] De esa Colina, donde a cada hora sois visto, $y$ veis a nuestros ciudadanos, donde la castellana fe os adora 260.-- constante desde siglos muy lejanos; de Vos pendiente en esa Cruz implora Palencia los socorros soberanos, y con ella en clamar proseguiremos, Señor, salvadnos, porque perecemos. 


\section{NOTAS}

1. Tolrá, Juan José (1804), mss., A la milagrosa ymagen del santíssimo Christo del Otero que se venera extra-muros de la ciudad de Palencia sobre las presentes calamidades: Canto votivo / en Palencia, por dn. Juan Josef Tolrrá de la extinguida Compañía de Jesús, Madrid, Archivo de la Real Academia de la Historia, mss. 9/2641 (38), 10 hojas. Colección Cortes, Olim: 9-13-7 2641.

2. Archivum Romanum Societatis lesu, Roma (ARSI), mss. "Antonio Morey, Summarium vitae P. Joannis Tolrá, quator votor: profess. in Domo Probation. Matrit. defuncti 10 mart. 1830". Siete folios. Hay una copia del original latino y una traducción anónima al castellano del siglo XIX en el Archivo de la Provincia de Toledo en el Colegio de Alcalá de Henares. En adelante, Morey, 1830.

3. Ese año Hervás estaba publicando El hombre físico o anatomía humana físico-médica (Hervás, 1800).

4. Morey, 1830, f. 6. Para la referencia completa, véase la nota 3.

5. El cirujano Argüello lo presentó manuscrito al Ayuntamiento palentino en septiembre de 1802, por lo que debió ser impreso a continuación, dada su finalidad práctica y profiláctica. Hay un ejemplar en el Archivo Municipal de Palencia, donde lo vio Riera Palmero, sin signatura.

6. En especial al Archivo Capitular de Palencia (ACP), para seguir en los Libros de Actas la intervención del cabildo catedralicio; al Archivo Diocesano de Palencia (ADP), en cuyos libros sacramentales se registran los muertos y nacidos; al Archivo Histórico Provincial de Palencia (AHPP), donde los protocolos notariales acogen distintos acuerdos gremiales y testamentos; y al Archivo Municipal de Palencia (AMP), cuyo Ayuntamiento tomaba diversas medidas para salir de la crisis.

7. AHN, Sección diversos, Serie general, fondo 1, Cabarrús, legajo 52, 1815.

8. "Fiebre voraz", verso 89 del Canto votivo.

9. Para Tolrá, los rigores de esa mala climatología "comunican su endémica influencia / al campo, a la ciudad y habitadores / de la triste Provincia de Palencia" (versos 42-45 del Canto votivo).

10. "El pan a la ciudad viene pidiendo", verso 60 del Canto votivo.

11. Este azote es, para Tolrá, "sangriento, fulminante y ruinoso", a cuya saña "terror, fiebre, dolor, muerte acompaña" (versos 78-80 del Canto votivo).

12. $A M P$, Libro de acuerdos de 1803. Sesión 1.7.1803.

13. Un traslado de esta Real Orden puede verse en el $A C P$, Actas capitulares, libro de 1804, sesión de 7 de enero, y también en AMP, Libro de acuerdos de 1804, sesión de 9 de enero.

14. ACP, Actas capitulares, libro de 1805 .
15. “...tantas formas muda, / que cuán su ensayo sea, hasta hoy se duda" (versos 95-96 del Canto votivo).

16. Lucas 8, 23-25: "Mientras ellos navegaban, se durmió. Se abatió sobre el lago una borrasca; se inundaba la barca y estaban en peligro. Entonces, acercándose, le despertaron, diciendo: « $i$ Maestro, Maestro, que perecemos!» $\mathrm{El}$, habiéndose despertado, increpó al viento y al oleaje, que amainaron, y sobrevino la bonanza. Entonces les dijo: «¿Dónde está vuestra fe?» Ellos, llenos de temor, se decían entre sí maravillados: "Pues ¿quién es éste, que impera a los vientos y al agua, y le obedecen?»"

17. Respestivamente, "Señor, salvadnos, porque perecemos", tan repetido a lo largo del Canto votivo de Tolrá, y "el Señor es mi fuerza y fortaleza, mi refugio en el peligro" (Jeremías 16,19$)$.

18. Cf. Deuteronomio 9, 18-25; Primer libro de Samuel 8, 3335; Segundo libro de las Crónicas 20, 9; Juan 3, 5-10.

19. A los salmos de súplica del Salterio se asemejan, por la forma y por el contenido, textos como Isaías 59, 9-15; 63, 7-64, 11; Lamentaciones 5; Jeremías 14, 2-9 y 14, 17-22, etc.

20. Esta estrofa concluye de la siguiente manera: "a Vos clama, cual nunca, desolado, / teniendo ya los últimos extremos, / Señor, sálvanos, porque pereceremos" (versos 6-8).

21. "De Vos pendiente en esa Cruz implora / Palencia los socorros soberanos, / y con ella en clamar proseguiremos, / Señor, salvadnos, porque pereceremos" (versos 261-264).

22. El labrador ve "el campo agostado antes que verde", "sus granos y fatiga infeliz pierde" (verso 51).

23. "Mas la ciudad envuelta en sus pesares, / ni los ajenos remedios pudiendo, / de uno y otro dolor se compadece, / y uno con otro mutuamente crece" (versos 61-64).

24. AMP, Libro de acuerdos de 1804. Sesión del 3 de enero de 1804.

25. "Y si antes las abría francamente, / hoy cierra las puertas al famélico e indigente" (versos 71-72).

26. De las que dice "que son serpientes ocultas, que abrigamos; / mas de ellas solas nunca nos quejamos" (versos 247-249).

27. "Sed Vos también nuestra salud" (verso 256).

28. Los salmos con estas características se denominan "imprecatorios". A ellos pertenecen, especialmente, los Salmos 58; 83 y 89 (Ravasi, 1985, pp. 253-260; Tabet, 2007, pp. 102-103).

29. Esta numeración hace referencia a los folios del mss. $9 / 2641(38)$ 
30. Alusión al Evangelio de Lucas (8, 23-25).

31. El cerro u otero en el que estaba el Cristo palentino.

32. Hacía tres años que había empezado la crisis agrícola y sanitaria en Palencia. Argüello comenta que desde el equinoccio de 1799 empezaron las "aguas con mucha abundancia y continuaron toda esta estación, invierno y primavera hasta cerca del estío con blandura y suavidad de los vientos, lo que motivó que los labradores no pudiesen sembrar todo su barbecho" (Argüello, 1802, pp. 12-13).

33. Tolrá parece indicar que en el verano era cuando más virulencia alcanzaba la epidemia, que aflojaba en las estaciones del frío de los tres años anteriores (1800-1804).

34. Con toda probabilidad Tolrá se está refiriendo a las prolongadas malas cosechas entre 1802 y 1804

35. El conocimiento e introducción en España de las "modernas teorías miasmáticas" y las prácticas fumigatorias están basadas en los avances de la química de los últimos años del siglo XVIII y principios del XIX (García Colmenares, 1998, p. 130).

36. Alusión a la citada teoría miasmática de la enfermedad formulada por Thomas Sydenham (1624-1689), en Sydenham, Thomas (1676), Observationes medicae circa morborum acutorum historiam et curationem, London, G. Kettilby, y Giovanni María Lancisi (1654-1720), en Lancisi, Giovanni María (1717), De noxiis paludum effluviis eorumque remediis, Roma, J. M. Salvioni.

37. La hambruna, causada por la sequía.

38. Los vacceos (vaccei) fueron un pueblo prerromano asentado en el sector central de la cuenca del Duero. Su existencia está probada al menos desde el siglo III a. C. (Romero y Sanz, 2010).

39. En otros escritos Tolrá no era "loista".

40. En esta visión aterradora de la epidemia, se entrevé el tópico tradicional de la muerte que a todos llega, sin distinciones. El mejor ejemplo de este tópico lo hallamos en la Oda II 3 de Horacio, bien conocida por Tolrá (Mañas Viniegra, 2006, pp. 269-284).

41. En la mitología romana, el Averno era la entrada al inframundo.

42. Esculapio, el Asclepio para los griegos, es el héroe y el dios de la Medicina. Su arte era practicado por los llamados Asclepíadas, siendo el más célebre Hipócrates.

43. La epidemia presentó muy diversos síntomas, descritos en la estrofa siguiente, lo cual desconcertaba a los médicos de la época.

44. Obsérvese la repetición de la onomatopéyica palabra "ayes" en esta estrofa y en la siguiente.
45. Luego de dedicar la primera parte a los males físicos, en la segunda, que comienza a continuación, se tratan los males espirituales y morales.

46. Nota de Tolrá en ladillo: "San Ambrosio libro 4, in capítulo 4 Lucas".

47. De las pasiones.

48. Parece que Tolrá había leído las Poesías de Meléndez, publicadas en Valladolid (1797, 3 tomos), en concreto, la oda $\mathrm{XIX}$, Inmensidad de la Naturaleza, y bondad inefable de su Autor (Meléndez Valdés, 2004, pp. 780-785).

49. La Pentápolis designa la región donde se encontraban Sodoma, Gomorra, Adama y Seboim, las ciudades cananeas destruidas por la ira de Dios (Génesis 19, 24-25).

50. Sennacherib o, mejor, Senaquerib (705 a. C.-681 a. C.), rey asirio que restableció Nínive como capital de su reino. En el Antiguo Testamento se cuenta que Jerusalén fue liberada por el Señor cuando envió a su ángel para que hiriera al ejército asirio, forzando a Senaquerib a regresar a su tierra de origen (Libro segundo de los Reyes 19, 35-36; Libro segundo de las Crónicas 32, 21; e Isaías 37, 36-37).

51. Italianismo, de instabile.

52. Nota de Tolrá: “Evangelio de San Juan 6, versículo 69".

53. El "de Vos figura" se refiere al Cristo del Otero. Es catáfora, porque Tolrá anuncia el símbolo alegórico que expresará más adelante en las estrofas 29-32, en la que relata el episodio en el que Yahvé ordena a Moisés que coloque en alto una serpiente de metal, para que los israelitas, mirándola con fe, curen sus males, de la misma manera que los palentinos curarán si, arrepentidos de sus pecados, acuden a adorar al Cristo del Otero.

54. Ubicada al sur de Judea y del mar Muerto.

55. Nótese cómo en estos versos la imagen de la serpiente coincide con la ofrecida por los textos sagrados, donde este reptil era el símbolo de todo mal. Aunque la serpiente maligna aparece en el texto bíblico muy temprano y con mucho protagonismo, hay otros pasajes, como el narrado por Tolrá, en los que hallamos la figura de la serpiente con otras facetas más benignas, como en Éxodo 4, 2 y 16, 14. Esta visión opuesta para un mismo animal quasi mítico es mantenida también en Grecia y Roma.

56. Nota de Tolrá: "San Juan 3, versículo 14-15". 


\section{BIBLIOGRAFÍA}

Anes, Gonzalo (1970), Las crisis agrarias en la España moderna, Madrid, Taurus.

Argüello y Castrillo, Agustín (1802), Dictamen físico-médicopolítico sobre la epidemia de Tercianas que por cerca de tres años reyna en el Pays de Campos, y particularmente en su Capital, la Ciudad de Palencia, Palencia, Imprenta de Álvarez.

Astorgano, Antonio (2011), "Un jesuita expulso sangüesino rebelde: Francisco Javier Mariátegui, El ex jesuita oprimido", Príncipe de Viana, 252, pp. 181-252.

Baena Sáez, Rafael y otros (1988), "Profilaxis de la fiebre amarilla en Córdoba en los albores del siglo XIX: fumigaciones de orientación química", Minutos Menarini, 160, pp. 4-10.

Becerro de Bengoa, Ricardo (1874), El libro de Palencia, edición facsímil, Palencia, Caja España, 1993.

Bernini, Giuseppe (1953), Le preghiere penitenziali del salterio, Roma, Pontificia Univ. Gregoriana.

Carvalho, José Antonio (1972), "Hambre y enfermedad en Salamanca. Estudio de la repercusión de la crisis de subsistencias de 1803-1805", Asclepio, 24, pp. 225-266.

Díaz Palenzuela, Luis Ángel (2002), "Sanidad y educación en la ciudad de Palencia en el siglo XVIII: la salud y la medicina, las escuelas de primeras letras y otros centros de enseñanza", Publicaciones de la Institución Tello Téllez de Meneses (PITTM), 73, pp. 165-194.

Egido, Teófanes (1995), “Palencia en el Antiguo Régimen: espacio sacralizado". En: Actas del III Congreso de Historia Moderna de Palencia. Tomo III. Edad Moderna y Contemporánea, Palencia, Diputación Provincial, Departamento de Cultura, pp. 11-29.

Fernández Conde, Francisco Javier (2007), Prisciliano y el priscilianismo. Historiografía y realidad, Gijón, Ediciones Trea.

Fernández Morate, Segundo (2009), Cristo del Otero, Leyenda, tradición e historia, Palencia, Ayuntamiento, Concejalía de Cultura.

Franquesa, Pedro (1966), Introducción a los Salmos en la Sagrada Biblia, Barcelona, Editorial Regina.

García Colmenares, Pablo (1987), "Sociedad, sanidad y muerte en Palencia en el siglo XIX: la mortalidad y las crisis epidémicas". En: Actas del primer Congreso de historia de Palencia, vol. III, Edad moderna y contemporánea, Palencia, Diputación, pp. 686-87.

García Colmenares, Pablo (1998), Estancamiento demográfico y estabilidad social en Castilla (1750-1930). Las condiciones de vida en la Palencia contemporánea, Universidad de Valladolid.
García Ruipérez, Mariano (1999), Revueltas sociales en la Provincia de Toledo. La crisis de 1802-1805, Toledo, Instituto Provincial de Investigaciones y Estudios Toledanos.

Herrero Puyuelo, María Blanca (1987), “Aportación al Estudio Demográfico de la Parroquia de Santa María de Palencia en el siglo XVIII", PITTM, 56, pp. 217-248.

Hervás y Panduro, Lorenzo (1800), El hombre físico o anatomía humana físico-médica, 2 vols., Madrid, Real Arbitrio de Beneficencia.

Keller, Werner (1985), Y la Biblia tenía razón, Barcelona, Ediciones Omega.

Kondo, Agustín Y. (1990), La agricultura española del siglo XIX, Madrid, Editorial Nerea.

Lancisi, Giovanni María (1717), De noxiis paludum effluviis eorumque remediis, Roma, J. M. Salvioni.

Llopis Agelán, Enrique y Sánchez Salazar, Felipa (2014), "La crisis de 1803-1805 en las dos Castillas: subsistencias, mortalidad y colapso institucional". En: Comín Comín, Francisco y PiniIla Navarro, Vicente (coords.), XI Encuentro de Didáctica de la Historia Económica, Santiago de Compostela, 26 y 27 de junio de 2014 [en línea] disponible en: http://www.usc.es/ export/sites/default/es/congresos/xiedhe/papers/S2_4_ Llopis_Sanchez_TC.pdf. [Consultado el 3-mayo-2016].

Lomba, C. (2002), El Cristo del Otero, el extraño magnetismo de una imagen, Toledo, Real Fundación de Toledo-Museo Victorio Macho.

López Gómez, José Manuel (1994), “La epidemia palúdica de 1804 en las provincias de Burgos y Palencia". En: Actas del XXXIII Congreso Internacional de Historia de la Medicina: Granada-Sevilla, 1-6 septiembre, 1992, Sevilla, Sociedad Española de Historia de la Medicina, pp. 633-650.

Mañas Viniegra, Francisco Javier (2006), “El tópico de la muerte en la Oda 2, 3 de Horacio”. En: Cabanillas Núñez, Carlos Manuel y Calero Carretero, José Ángel (coords.), Actas de las IV Jornadas de Humanidades Clásicas, Mérida, Consejería de Cultura, pp. 269-284.

Marcos Martín, Alberto (1984), "Palencia en el siglo XVIII". En: González, Julio (coord.), Historia de Palencia, volumen II. Edades moderna y contemporánea, Palencia, Diputación Provincial, pp. 83-122.

Marcos Martín, Alberto (1985), Economía, sociedad, pobreza en Castilla: Palencia 1500-1814, Vol. II, Palencia, Diputación.

Meléndez Valdés, Juan (2004), Obras Completas, Madrid, Editorial Cátedra. Edición de Antonio Astorgano.

Morla Asensio, Víctor (1994), Libros sapienciales y otros escritos, Pamplona, Verbo Divino. 
Owens, John (1977), The Forgiveness of Sin. A Practical Exposition of Psalm 130, Michigan, Baker Book House.

Parcero Torre, Celia María (2003), “La división ideológica del clero de la diócesis de Palencia a través de los concursos parroquiales de 1823 y 1825". En: Buldain Jaca, Blanca Esther; Sepúlveda Muñoz, Isidro (coords.), La Iglesia española en la crisis del Antiguo Régimen, Madrid, Uned, pp. 305-322.

Pérez Moreda, Vicente (1980), La crisis de mortalidad en la España interior. Siglos XVI-XIX, Madrid, Siglo XXI.

Pérez Moreda, Vicente (1984), “Crisis demográficas y crisis agrarias: paludismo y agricultura en España a finales del siglo XVIII". En: Actas del Congreso de historia rural, siglos XVXIX, Madrid, Universidad de Madrid, pp. 333-354.

Peset Reig, Mariano y Peset Reig, José Luis (1972), Muerte en España: política y sociedad entre la peste y el cólera, Madrid, Seminarios y Ediciones.

Ravasi, Gianfranco (1985), Il libro dei Salmi: commento e attualizzazione, Vol. III, Bolonia, Centro Editoriale Dehoniano.

Ravasi, Gianfranco (2008), "Dal profondo grido a te (Salmo 130)". En: Bonora, Antonio; Priotto, Michelangelo (coords.), Libri Sapienziali e altri scritti, Turín, Leumann, pp. 323-332.

Reder Gadow, Marion (2013), "El exvoto: de la promesa a la materialización”. En: Campos y Fernández de Sevilla, Francisco Javier (coord.), El Patrimonio Inmaterial de la Cultura Cristiana, San Lorenzo de El Escorial, Ediciones Escurialenses, pp. 147-158.

Reguera Useros, Alberto (1985) "La Sociedad Económica de Amigos del País de Palencia en el siglo XVIII", PITTM, 52, pp. 389-405.

Revuelta González, Manuel (2008), "Aspectos religiosos en la Guerra de la Independencia y su repercusión en Palencia", PITTM, 79, pp. 155-178.

Riera Palmero, Juan (1982), Estudios y documentos sobre arroz y paludismo en Valencia. Siglo XVIII, Valladolid, Universidad de Valladolid.
Riera Palmero, Juan (1987), “Epidemiología y tercianas en Tierra de Campos (1800-1802)". En: Actas del primer Congreso de Historia de Palencia. Vol. III. Edad moderna y contemporánea, Palencia, Diputación Provincial, pp. 671-678.

Romero Carnicero, Fernando; Sanz Mínguez, Carlos (eds.) (2010), De la Región Vaccea a la Arqueología Vaccea, Valladolid, Centro de Estudios Vacceos "Federico Wattenberg".

San Martín Payo, Jesús (1985), El Cristo del Otero y Santo Toribio, Palencia, Diputación Provincial.

Sánchez, Santos (1805), Colección de pragmáticas, cédulas, provisiones, autos acordados y otras providencias generales expedidas por el Consejo Real en la reinado del señor don Carlos IV, cuya observancia corresponde a los tribunales y jueces ordinarios del reino, y a todos los vasallos en general, por don Santos Sánchez, oficial de la escribanía de Cámara y gobierno del mismo Consejo. Tomo III. Comprende las respectivas a los años desde 1801 al 1804 inclusive. Tercera edición, Madrid, Imprenta de don José del Collado, pp. 415-418.

Sydenham, Thomas (1676), Observationes medicae circa morborum acutorum historiam et curationem, London, G. Kettilby.

Tabet, Miguel Angel (2007), Introducción al Antiguo Testamento. Tomo 3. Libros poéticos y Sapienciales, Madrid, Ediciones Palabra.

Villalba, Joaquín de (1802-1803), Epidemiología española ó historia cronológica de las pestes, contagios, epidemias y epizootias que han acaecido en España desde la venida de los cartagineses hasta el año 1801, con noticia de algunas otras enfermedades de esta especie que han sufrido los españoles en otros reynos, y de los autores nacionales que han escrito sobre esta materia, asi en la península como fuera de ella, Madrid, Mateo Repullés y Fermín Villalpando (Reeditada con estudio preliminar de Antonio Carreras Panchón con el título Joaquín de Villalba (1752-1807) y los orígenes de la historiografía médica española, Málaga, Universidad, 1984, 2 vols.). 